\title{
First report of Rhizoctonia solani AG-4 HG-I causing crown rot on Abelmoschus manihot in Italy
}

\author{
Angelo Garibaldi ${ }^{1} \cdot$ Giulia Tabone ${ }^{1} \cdot$ Domenico Bertetti $^{1} \cdot$ Maria Lodovica Gullino $^{1}$
}

Received: 2 March 2020 / Accepted: 2 June 2020 / Published online: 3 August 2020

(C) Società Italiana di Patologia Vegetale (S.I.Pa.V.) 2020

Keywords Ornamental plants · Soil-borne pathogens · Anastomosis group (AGs)

During the fall 2019, 25 out of 50 two-month-old plants of Abelmoschus manihot (Syn: Hibiscus manihot), Malvaceae family, grown in pots in an experimental greenhouse located in Grugliasco (Northern Italy) showed stunting, leaf withering, crown rot and died seven days after the appearance of the first symptoms. Colonies of a fungus with the characteristics of Rhizoctonia solani (Sneh et al. 1991) were isolated with a frequency of $90 \%$. Colonies grown on PDA for 30 days showed a light brown, compact mycelium with hyphae developing radially. Sclerotia developed after 20 days and they were few, small (1.1 $\mathrm{mm}$ in diameter), rounded, dark-brown with rusty surfaces. The anastomosis group was determined by pairing (three replicates/pairing) the isolate 19/61 with R. solani isolates belonging to the groups AG-1, AG-2, AG4, AG-7, AG-11. The isolate 19/61 formed anastomosis only with $R$. solani AG-4 group with a low fusion frequency $(<30 \%)$. A PCR was carried out with primers ITS1/ITS4 (GenBank Accession No. MN822713) and the sequence, analyzed using BLASTn, showed 100\% homology with R. solani AG-4 HG-I (MN106332). The morphological characteristics of the sclerotia and the high DNA base sequence homology determined that the isolate $19 / 61$ belongs to the subgroup HG-I of $R$. solani AG-4 (Sherwood 1969). Three repeated pathogenicity tests ( 6 plants for each test), were

Giulia Tabone

giulia.tabone@unito.it

Centre of Competence for the Innovation in the Agro-Environmental Sector (AGROINNOVA), University of Torino, Largo Paolo Braccini 2, 10095 Grugliasco, Torino, Italy carried out on 30-day-old plants of A. manihot. Two mycelial plugs ( $8 \mathrm{~mm}$ in diameter) of the isolate $19 / 61$ were placed at the crown of the plants that were maintained in a greenhouse at temperatures ranging from 20 to $25{ }^{\circ} \mathrm{C}$. For each trial, six plants were treated with sterile PDA plugs and used as controls. After seven days, the inoculated plants died while the controls remained healthy. $R$. solani AG-4 HG-I was reisolated with a frequency of $>90 \%$. $R$. solani was reported on several species of Hibiscus (Farr and Rossman 2020). This is the first report of $R$. solani on A. manihot in Italy. The spread of $R$. solani on Hibiscus spp. could represent a serious problem for their cultivation, in particular for H. syriacus widely used in hedges.

\section{References}

Farr DF, Rossman AY (2020) Fungal Databases, U.S. National Fungus Collections, ARS, USDA. Retrieved February 25, 2020

Sherwood RT (1969) Morphology and physiology in four anastomosis groups of Thanatephorus cucumeris. Phytopathology 59:19241929

Sneh B, Burpee L, Ogoshi A (1991) Identification of Rhizoctonia species. APS, St Paul

Publisher's note Springer Nature remains neutral with regard to jurisdictional claims in published maps and institutional affiliations. 